\title{
PARTIAL CASES OF STRESSED-DEFORMED CONDITION OF CASING AND PUMP COMPRESSOR PIPES
}

\author{
Vitalii VASYLYSHYN, Iryna TARAS, Iryna BEKISH, Olena KORNUTA, Volodymyr KORNUTA \\ Ivano-Frankivsk National Technical University of Oil and Gas
}

\begin{abstract}
:
Threaded joints are the most technological for piling up in the fields. However, violations of standard threaded joints account for $70 \%$ of all complications in pipe processing and production. These malfunctions result in significant material losses, reduced well productivity, and contamination of the wells and environmental pollution. Particularly acute is the loss of these sealed joints during exploration and development of gas and gas condensate fields. The necessary increase in volumes and intensification of hydrocarbon energy production is envisaged by the increase of drilling depth, construction of slopes and horizontal wells. Horizontal drilling and fracturing are used to produce shale gas. The efficiency and safety of the operation of oil and gas wells in complex mining and technical conditions depend on the quality and reliability of casing and pumping columns, which requires the modernization of machinery and technology for the installation of wells. The most technological for column fitting in the fisheries sector is threaded joints. However, breach of standard threaded connections causes $70 \%$ of all complications with pump housings and columns. This leads to significant material losses, reduced production of raw materials, contamination of the interior and the environment. Therefore, the urgent task is to improve the threaded joints by increasing their reliability and efficiency under heavy workloads.
\end{abstract}

Key words: tubing, stress-strain state, fatigue life, tightening torque

\section{INTRODUCTION}

Ukraine remains in the country, economically the most increasing is the measure that holds back the lack of its own energy resources. Due to this, the novels of Ukraine are all active in the issues of world classification. One of such warehouses is being realized in the developed period of new carbohydrate deposits, extraction of unconventional materials (shale gas, metallic coal deposits, gas of necessary collectors). This energy resource offers greater interest to the global public in increasing time, which includes fuel and renewable energy. Private is the fact that the shale product is to be placed within the boundaries that are being implemented in Ukraine and, in addition, it is possible to achieve the expansion of the gas pipeline, which can receive prompt delivery. In addition, it does a great job of building new pipelines. Necessary expansion and intensive verification of production of hydrocarbon energy is carried out with the help of deep structure, construction of inclined and horizontal wells. For the extraction of shale inclined horizontal drilling and fracturing. The efficiency and safety of oil and gas wells in mining and construction residues remain from the reliability and reliability of the pump columns, which needs to be upgraded, used and made by the wells.
The most productive product for making columns in the appropriate code is the threaded coupling. They test standard threaded products that are supported by $70 \%$, and more than $70 \%$ are left with application and pump colonies. This applies to significant actual losses that ensure the efficiency of raw material extraction, pollution above the ground and longevity. The Special was keenly aware of the loss of sealed substances that reached the size and expansion and production of gas and gas condensate fields. Well tightness is the highest safety component of shale extraction.

Pump tubes (tubing) operated in wells with replacements greater than $60 \%$ and deep wells with curvatures greater than 140 should not use the installed service terminal. The previous failure of the tubing worked in the aggressive workplaces of plasma waters, contaminated with acids, corrosive gases, hydro-corrosion action, active content, and is also in free destruction under the influence of existing loads. and performance for high operating conditions. To solve them, it is necessary to carry out theoretical and experimental studies, on the basis of which it is possible to develop effective methods and means of increasing the reliability of oil and gas wells. 


\section{THE PURPOSE OF THE WORK}

The purpose of this work is to increase the reliability and efficiency of the pipe column threaded connections during the operation of oil and gas wells by increasing the strength of the casing and tubing threaded connections under the variable irregular loads.

\section{LITERATURE REVIEW}

The purpose of this work is to increase the reliability and efficiency of the pipe column threaded connections during the operation of oil and gas wells by increasing the strength of the casing and tubing threaded connections under the variable irregular loads. As already mentioned $[6,14,15,16,17,18,19,20,21,22,23]$, the most common tubing failure is caused by threaded connections, in particular: fracture (34\%); loss of tightness (12\%); the connection is not screwed up - the critical tension and geometric parameters of the profile $(43 \%)$; the connection is not screwed off - thread jamming (11\%). Here is also presented an analysis of operational disruptions at Ukrnafta OJSC is presented, which showes that the failures of the threaded connection of tubing were: in $2008-32.8 \%$, in 2009. $-34.2 \%$, in $2010-32.2 \%$.

It is noted that in oil production under difficult conditions, the pipes and their threaded connections are exposed not only to the intense corrosion of the aggressive environment but also to considerable alternating mechanical loads, which leads to the active destruction of the pipe thread. The reasons for this state of emergency are more than sufficient, but the main ones are the influence of the aggressive environment and the stress-strain state. In particular, according to the studies of A.N. Adonin, in the deep-pumping method of hydrocarbon raw material production, the tubing column is loaded with the following forces: the dead-load tensile force and a part of the liquid weight force in tube, which is not transmitted to the rods as they move upwards; the additional tensile force of the fluid column weight acting on the receiving valve as the point of the rod suspension moves downwards; friction forces resulting from reciprocating movement of the pump rod column. Additionally, bending moments may occur in the tubing cross-section, the causes of which are curved segments of well and oscillations.

The combined effect of the aforementioned force factors can lead to significant axial and radial deformations of the tubing, which, moreover, are variable in time.

\section{METHODOLOGY OF RESEARCH}

An important direction for improving the reliability and safety of well construction and operation is to improve the design and manufacturing technology of casing joints. The loss of working capacity of the casing is associated with the loss of the required strength and tightness of its coupling threaded connections. Even if the geometrical parameters of the threaded joints are fully aligned with the standards, such joints give rise to a wide dispersion of the force parameters of the interaction, which cannot withstand the load on the casing in the well. The tendency for the hidden underestimation of the strength and tight- ness of the threaded joints of the casing pipes and couplings with full compliance of their geometrical parameters with the standard is revealed, since the latter does not regulate the requirements of screwing with a given torque. The requirement that the end face of the coupling coincide with the end of the pipe thread is an unreliable criterion for the efficiency of the connection. Therefore, it is necessary to look for new technical solutions to increase the reliability and ensure the strength and tightness of the joints, to increase the efficiency of the clutch joints of casing pipes by design and technological methods. Important tasks to ensure the reliability of casing joints are: the correct choice of sealing oils or special sealants, the choice of grouting solutions and the process of cementing wells, creating the necessary elastic tension in the threaded connections. High performance and highest technical performance in the mounting and operation of wells in difficult mining and geological conditions and in inclined and horizontal wells showed high tight threaded connections with the metal-metal seals, but they have separate operating defects. Therefore, enhancing the strength and tightness of casing by improving connections with the integrated seal assembly is a topical and promising task.

\section{RESULTS OF RESEARCH}

The authors of $[6,15,16,17,22,23,24]$ have considered the change in stress in the mid-section of the thread length of the nipple and the coupling with an increase in the tightening torque under the bending moment acting on the connection (Fig. 1).

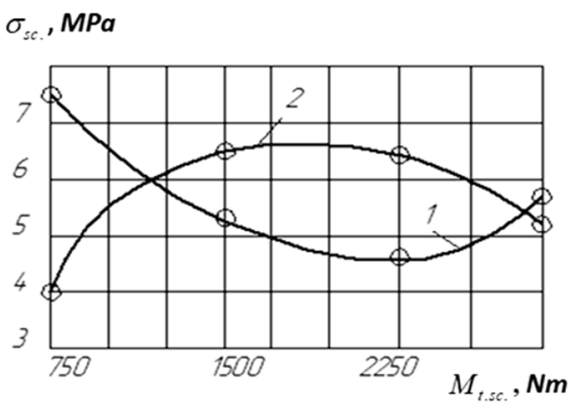

1 - nipple, 2 - coupling

Fig. 1 The distribution of stresses in the threaded connection $\mathrm{ZN}-75$, arising from the external load $\left(M_{s c}=1200 \mathrm{Nm}\right)$, at different $M_{t . s c \text {. }}$

These dependencies are compared with the dependencies establishing a relationship between the boundary amplitude and the screwing torque for connections made of Steel 45 . The boundary amplitude of the bending moments is the smallest for connections that are screwed up with $M_{t . s c .}=750 \mathrm{Nm}$. The stress in the nipple is maximum, and in the coupling - minimum. It follows that, with insuf-

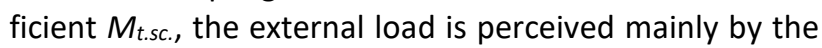
nipple. In connections screwed up with Mt.sc., the boundary amplitude significantly increased. The stress in the nipple sharply decreases, and in the coupling - increases. Thus, the increase in $M$ t.sc. leads to a favorable redistribution of stress in the connection parts. Fatigue fracture passes through the nipple, as there is tensile stress in it, and compressive stress in coupling when screwed up. 
Connections that are screwed up with $M_{t . s c .}=2250 \mathrm{Nm}$ have the highest boundary amplitude. Further increase of Mt.sc. up to $3000 \mathrm{Nm}$ leads to its decrease in comparison with the maximum value. The stress in the nipple begins to increase, and in the coupling - to decrease. This determines the relationship between the boundary amplitude of the connections, screwed up by different torques, and the stresses developed in the parts of the connection due to the bending moment acting on them. This can predict the optimum torque at which the boundary amplitude has the highest value.

Interpolation polynomial of the third degree was selected to represent the dependence of the stresses in the nipple (1) and the coupling (2) (Fig. 1) under the bending moment of external load at different $M_{\text {t.sc. }}[1,2,5,21,22,25]$. The expression of divided differences was used to create it $[13,15,16,20,21,22]$. The table of divided differences is developed (Table 1 ).

Table 1

The table of divided differences

\begin{tabular}{ccccc}
\hline $\begin{array}{c}(\boldsymbol{x}) \\
M_{t . s c .}\end{array}$ & $\begin{array}{c}(\boldsymbol{y}) \\
\sigma_{s c}, \\
\boldsymbol{k N m}\end{array}$ & $\begin{array}{c}\text { The first } \\
\text { differences }\end{array}$ & $\begin{array}{c}\text { The second } \\
\text { differences }\end{array}$ & $\begin{array}{c}\text { The third } \\
\text { differences }\end{array}$ \\
\hline $\boldsymbol{x}_{\mathbf{0}}$ & $y\left[x_{0}\right]$ & & & \\
$\boldsymbol{x}_{1}$ & $y\left[x_{1}\right]$ & $y\left[x_{0}, x_{1}\right]$ & & \\
$\boldsymbol{x}_{\mathbf{2}}$ & $y\left[x_{2}\right]$ & $y\left[x_{1}, x_{2}\right]$ & $y\left[x_{1}, x_{2}, x_{3}\right]$ & \\
$\boldsymbol{x}_{\mathbf{3}}$ & $y\left[x_{3}\right]$ & $y\left[x_{2}, x_{3}\right]$ & & $y\left[x_{0}, x_{1}, x_{2}, x_{3}\right]$ \\
\hline
\end{tabular}

Polynomial is presented using the agreed notation:

$$
\begin{gathered}
y(x)=y\left[x_{0}\right]+\left(x-x_{0}\right) y\left[x_{0}, x_{1}\right]+\left(x-x_{0}\right)(x- \\
\left.x_{1}\right) y\left[x_{0}, x_{1}, x_{2}\right]+\left(x-x_{0}\right)\left(x-x_{1}\right)(x- \\
\left.x_{2}\right) y\left[x_{0}, x_{1}, x_{2}, x_{3}\right]
\end{gathered}
$$

The tables of the numerical values of the divided differences calculated by the formula (1) and the data taken from Figure 1 were compiled (Table 2, 3).

\begin{tabular}{|c|c|c|c|c|}
\hline $\begin{array}{l}M_{t . s c .} \\
k N \boldsymbol{m}\end{array}$ & $\begin{array}{c}\sigma_{\mathrm{sc} .} \\
\mathrm{MPa}\end{array}$ & $\begin{array}{l}\text { The value of } \\
\text { the first } \\
\text { differences }\end{array}$ & $\begin{array}{c}\text { The value of the } \\
\text { second } \\
\text { differences }\end{array}$ & $\begin{array}{l}\text { The value of } \\
\text { the third } \\
\text { differences }\end{array}$ \\
\hline 0.75 & 7.50 & $\frac{5.20-}{150-}$ & $-0.333-(-3.067)$ & \\
\hline 1.50 & 5.20 & $\begin{array}{l}1.50-0.75 \\
4.95-5.20\end{array}$ & & $\frac{0.887-1.823)}{200.075}=-0.416$ \\
\hline $\begin{array}{l}2.25 \\
3.00\end{array}$ & $\begin{array}{l}4.95 \\
5.70\end{array}$ & $\begin{array}{l}2.25-1.50 \\
\frac{5.70-4,95}{3.00-2.25}=1.000\end{array}$ & $\frac{1.000-(-0.333)}{3.00-1.50}=0.887$ & \\
\hline
\end{tabular}

Table 2

The table of divided differences for the nipple 1 (Fig. 1)

Thus, for the nipple, the interpolation polynomial takes the form

$$
\sigma_{s c .}=-0.416\left(M_{t . s c}\right)^{3}+3.695\left(M_{t . s c .}\right)^{2}-9.743 M_{t . s c .}+
$$

where:

$\sigma_{\text {sc. }}$ screw up stress in threaded connection.

Taking a derivative of this expression and equating it to zero, it is possible to determine at what value of torque $M_{\text {t.sc. }}$ the stress $\sigma_{\text {sc.min }}$ has minimum and value of it.

\begin{tabular}{|c|c|c|c|c|}
\hline $\begin{array}{l}M_{t . s c .} \\
k N m\end{array}$ & $\begin{array}{c}\sigma_{\text {sc. }} \\
M P a\end{array}$ & $\begin{array}{c}\text { The value of } \\
\text { the first } \\
\text { differences }\end{array}$ & $\begin{array}{c}\text { The value of the } \\
\text { second } \\
\text { differences }\end{array}$ & $\begin{array}{c}\text { The value of the } \\
\text { third } \\
\text { differences }\end{array}$ \\
\hline 0.75 & 4.00 & \multirow{4}{*}{$\begin{array}{l}\frac{6.45-4.00}{1.50-0.75}=3.267 \\
\frac{6.40-6.45}{2.25-1.50}=-0.067 \\
\frac{5.25-6.40}{3.00-2.25}=-1.533\end{array}$} & \multirow{4}{*}{$\begin{array}{l}\frac{-0.067-3.267}{2.25-0.75}=-2.222 \\
\frac{-1.533+0.067}{3.00-1.50}=-0.977\end{array}$} & \multirow{4}{*}{$\frac{-0.977+2.222}{3.00-0.75}=0.553$} \\
\hline 1.50 & 6.45 & & & \\
\hline 2.25 & 6.40 & & & \\
\hline 3.00 & 5.25 & & & \\
\hline
\end{tabular}

$$
M_{\text {t.sc. }}=1.9814 \mathrm{KNm} \text {, at } \sigma_{\text {sc. } \min }=4.869 \mathrm{MPa}
$$

Table 3

The table of divided differences for the coupling 2 (Fig. 1)

For the coupling, the interpolation polynomial takes the form:

$\sigma_{s c .}=0.553\left(M_{t . s c}\right)-4.710\left(M_{t . s c}\right)^{2}+11.687 M_{t . s c}-2.348$. Taking a derivative of this expression and equating it to zero, it is possible to determine at what value of torque $M_{\text {t.sc. }}$ the stress $\sigma_{\text {sc.min }}$ has maximum and value of it.

$$
M_{t . s c .}=1.83 \mathrm{kNm} \text { at } \sigma_{s c \text {. } \min }=6.665 \mathrm{MPa}
$$

For connections that are screwed up with $M_{t . s c .}=750 \mathrm{Nm}$, $M_{\text {t.sc. }}=1500 \mathrm{Nm}, M_{\text {t.sc. }}=2250 \mathrm{Nm}$, these stress are 68.0 $\mathrm{N} / \mathrm{mm}^{2}, 135.0 \mathrm{~N} / \mathrm{mm}^{2}, 202.0 \mathrm{~N} / \mathrm{mm}^{2}$, respectively [19].

Consequently, empirical formulas can be obtained in the form of third- and fourth-degree polynomials to determine the intensity of normal force distribution along the thread length by previous calculating. These formulas and calculations can also be used for particular cases of the stress-strain state of the casing.

The stress and displacement of a long circular cavity cylinder (casing), which is under normal external $p_{e}$ and internal $p_{i}$ pressures, evenly distributed on the lateral surface are considered as followed (Fig. 2).

Denoting the components of the stress tensor at an arbitrary point of the cylinder in cylindrical coordinates $\rho, \varphi, z$ as:

$$
\left\{\begin{array}{ccc}
\sigma_{\rho} & \tau_{\rho \varphi} & \tau_{\rho z} \\
\tau_{\varphi \rho} & \sigma_{\varphi} & \tau_{\varphi z} \\
\tau_{z \rho} & \tau_{z \varphi} & \sigma_{z}
\end{array}\right\}
$$

and keeping in mind, it is the polar symmetric problem, in this case, and there are two boundary conditions $\sigma_{\rho=r 1}=-p_{i}$ and $\sigma_{\rho=r 0}=-p_{e}$, the stress function is taken in form $\psi=A \log \rho+C \rho^{2}$

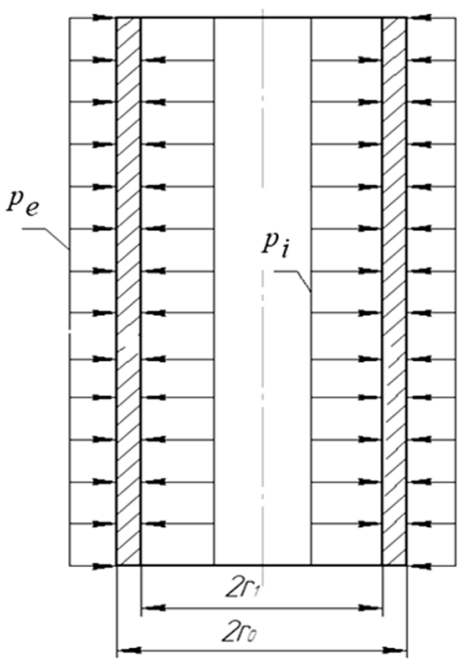

Fig. 2 Scheme of pressures $p_{e}$ and $p_{i}$ evenly distributed on the lateral surface of a long cavity circular cylinder 
Based on the formulas considered by the authors $[2,3,7$, 15, 16, 24]:

$$
\begin{gathered}
\sigma_{\rho}=\frac{1}{\rho} \frac{d \psi}{d \psi}=\frac{A}{\rho^{2}}+B(1+2 \ln \rho)+2 C, \\
\sigma_{\varphi}=\frac{d^{2} \psi}{d \rho^{2}}=-\frac{A}{\rho^{2}}+B(3+2 \ln \rho)+2 C, \\
\tau_{\rho \varphi}=\tau_{\varphi \rho}=0,
\end{gathered}
$$

the stresses will make:

$$
\sigma_{\rho}=\frac{A}{\rho^{2}}+2 C, \sigma_{\varphi}=-\frac{A}{\rho^{2}}+2 C, \tau_{\rho \varphi}=\tau_{\varphi \rho}=0 .
$$

Using the boundary conditions according to $[1,2,16,20]$, the stresses will be equal

thence

$$
A=\frac{r_{1}^{2} r_{0}^{2}\left(p_{e}-p_{i}\right)}{r_{0}^{2}-r_{1}^{2}}, 2 C=\frac{r_{1}^{2} p_{i}-r_{0}^{2} p_{i}}{r_{0}^{2}-r_{1}^{2}},
$$

$$
\begin{aligned}
& \sigma_{\rho}=\frac{1}{r_{0}^{2}-r_{1}^{2}}\left[r_{1}^{2} p_{i}-r_{0}^{2} p_{e}+\frac{r_{1}^{2} r_{0}^{2}}{\rho^{2}}\left(p_{e}-p_{i}\right)\right], \\
& \sigma_{\varphi}=\frac{1}{r_{0}^{2}-r_{1}^{2}}\left[r_{1}^{2} p_{i}-r_{0}^{2} p_{e}-\frac{r_{1}^{2} r_{0}^{2}}{\rho^{2}}\left(p_{e}-p_{i}\right)\right],
\end{aligned}
$$

if $u_{\rho}, u_{\varphi}, u_{z}$ are components of displacement $u_{\rho},\left(u_{\varphi}=0\right)$ equations must be integrated to determine displacement

$$
\begin{gathered}
e_{\rho \rho}=\frac{1}{E}\left(\sigma_{\rho}-v \sigma_{\varphi}\right), e_{\varphi \varphi}=\frac{1}{E}\left(\sigma_{\varphi}-v \sigma_{\rho}\right), e_{\rho \varphi}= \\
\frac{2(1+v)}{E} \tau_{\varphi \rho}
\end{gathered}
$$

The equations for this problem look like:

$$
E_{1} \frac{d u_{\rho}}{d \rho}=\sigma_{\rho}-v_{1} \sigma_{\varphi}, E_{1} \frac{u_{\rho}}{\rho}=\sigma_{\varphi}-v_{1} \sigma_{\rho} .
$$

From equations ( 3 ) formula is obtained

$$
u_{\rho}=\frac{1}{2 G\left(r_{0}^{2}-r_{1}^{2}\right)}\left[(1-2 v)\left(r_{1}^{2} p_{i}-r_{0}^{2} p_{e}\right) \rho+\frac{r_{1}^{2} r_{0}^{2}}{\rho}\left(p_{i}-p_{e}\right)\right] .
$$

The next step in this research is to determine the stresses and displacement of a circular cavity cylinder of length $h$ (casing), resting on an absolutely rigid and flawless plane and being under normal external $p_{e}$ and internal $p_{i}$ pressures, evenly distributed on the lateral surface (Fig. 3).

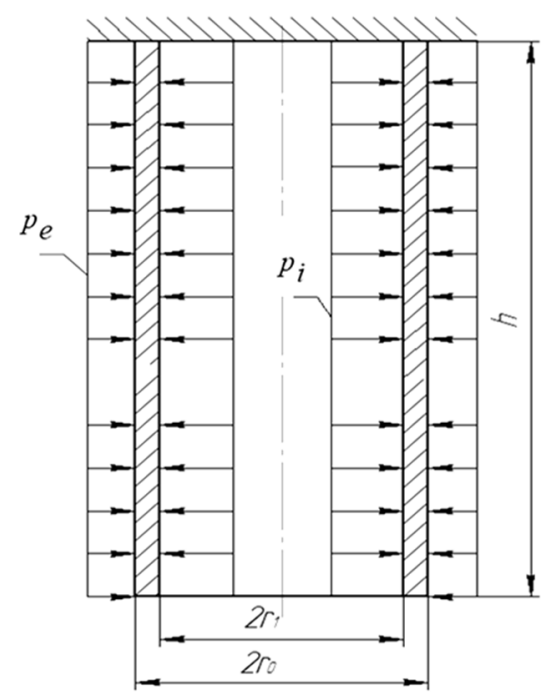

Fig. 3 Scheme of pressures $p_{e}$ and $p_{i}$ evenly distributed on the lateral surface of a cavity circular cylinder of length $h$, resting on an absolutely rigid and flawless plane

Stresses and deformations are expressed through one harmonic function $\psi_{3}=\psi$ in the case of axisymmetric deformation for the solids of revolution:

$$
\begin{gathered}
2 G u_{\rho}=-\frac{\delta^{2} \psi}{\delta \rho \delta z} ; u_{\varphi}=0 ; 2 G u_{z}=\left[2(1-v) \nabla^{2}-\frac{\delta^{2}}{\delta z^{2}}\right] \psi+\delta ; \\
\sigma_{\rho}=\frac{\delta}{\delta z}\left(v \nabla^{2}-\frac{\delta^{2}}{\delta \rho^{2}}\right) \psi ; \tau_{\varphi \rho}=\tau_{\rho \varphi}=\tau_{z \rho}=\tau_{\varphi z}=0 ; \\
\sigma_{\varphi}=\frac{\delta}{\delta z}\left(v \nabla^{2}-\frac{1}{\rho} \frac{\delta}{\delta \rho}\right) \psi ; \sigma_{z}=\frac{\delta}{\delta z}\left[(2-v) \nabla^{2}-\frac{\delta^{2}}{\delta z^{2}}\right] \psi \\
\tau_{z \rho}=\tau_{\rho z}=\frac{\delta}{\delta \rho}\left[(1-v) \nabla^{2}-\frac{\delta}{\delta z^{2}}\right] \psi
\end{gathered}
$$

where:

$$
\nabla^{2}=\frac{\delta^{2}}{\delta \rho^{2}}+\frac{1}{\rho} \frac{\delta}{\delta \rho}+\frac{\delta^{2}}{\delta z^{2}}
$$

$\delta$ - arbitraty constant.

By substitution there is checked two equations of equilibrium and four equations of continuity of deformations are satisfied for a given stress system if

$$
\nabla^{2} \nabla^{2} \psi=0 \text {. }
$$

To define the function $\psi$ it is useful to express it as power series of variable $z$ whose coefficients are unknown functions $\rho$ to define it:

$$
\begin{gathered}
\psi(z, \rho)=\sum_{k=0}^{4} f_{k}(\rho) z^{k}=f_{0}(\rho)+f_{1}(\rho) z+f_{2}(\rho) z^{2}+ \\
f_{3}(\rho) z^{3}+f_{4}(\rho) z^{4} .
\end{gathered}
$$

Substituting this expression into the biharmonic operator $\nabla^{2} \nabla^{2} \psi=\left(\frac{\delta^{4}}{\delta \rho^{4}}+\frac{2}{\rho} \frac{\delta^{3}}{\delta \rho^{3}}-\frac{1}{\rho^{2}} \frac{\delta^{2}}{\delta \rho^{2}}+\frac{1}{\rho^{3}} \frac{\delta}{\delta \rho}+2 \frac{\delta^{4}}{\delta \rho^{2} \delta z^{2}}+\frac{2}{\rho} \frac{\delta^{3}}{\delta \rho \delta z^{2}}+\right.$
$\left.\frac{\delta^{4}}{\delta z^{4}}\right) \psi=0$

and zeroing the coefficients to the same degrees $z$, we obtain differential equations to determine unknown functions $f_{i}$. These equations are of the Euler type and are integrated into elementary functions. The result of integration is expressed by the following formulas:

$$
\begin{gathered}
f_{0}(\rho)=A_{0}+B_{0} \ln \rho+C_{0} \rho^{2}+D_{0} \rho^{2} \ln \rho+\frac{1}{4}\left(\frac{9}{4} B_{4}+\frac{1}{2} D_{2}-\right. \\
\left.\frac{3}{2} A_{4}-C_{2}\right) \rho^{4}-\frac{1}{8}\left(3 B_{4}+2 D_{2}\right) \rho^{4} \ln \rho+\frac{1}{8}\left(C_{4}-\frac{5}{6} D_{4}\right) \rho^{6}+ \\
\frac{D_{4}}{8} \rho^{6} \ln \rho, \\
f_{1}(\rho)=A_{1}+B_{1} \ln \rho+C_{1} \rho^{2}+D_{1} \rho^{2} \ln \rho+\frac{3}{4}\left(\frac{D_{3}}{2}-C_{3}\right) \rho^{4}- \\
\frac{3}{4} D_{3} \rho^{4} \ln \rho, \\
f_{2}(\rho)=A_{2}+B_{2} \ln \rho+C_{2} \rho^{2}+D_{2} \rho^{2} \ln \rho+\frac{3}{2}\left(\frac{D_{4}}{2}-C_{4}\right) \rho^{4} \\
-\frac{3}{2} D_{4} \rho^{4} \ln \rho, \\
f_{3}(\rho)=A_{3}+B_{3} \ln \rho+C_{3} \rho^{2}+D_{3} \rho^{2} \ln \rho, \\
f_{4}(\rho)=A_{4}+B_{4} \ln \rho+C_{4} \rho^{2}+D_{4} \rho^{2} \ln \rho .
\end{gathered}
$$

For boundary conditions there are:

under $\rho=r_{1}, \sigma_{p}=-p_{i}, \tau_{\rho z}=0$

under $\rho=r_{0}, \sigma_{p}=-p_{e}, \tau_{\rho z}=0$

under $z=0, \sigma_{z}=\tau_{\rho z}=0$

under $z=h, u_{z}=0$.

Analysis of the function $\psi$ and boundary conditions allows us to make the following conclusions:

- the function $\psi$ depends on the odd functions $f_{n}$. Even functions characterize the pressure proportional to the first-degree $z$;

- in order that $\tau_{\rho z}=0$ for $\rho=r_{1}, \rho=r_{0}$, must be equal to zero constants $D_{1}, B_{3}, C_{3}, D_{3}$

- constant $A_{1}$ does not affect the stressed and deformed state.

Taking into account the listed conditions the following is obtained

$$
\psi(z, \rho)=\left(B_{1} \ln \rho+C_{1} \rho^{2}\right) z+A_{3} z^{3} .
$$

Composing expressions for stresses and displacements and satisfying the boundary conditions, it is found out:

$$
\begin{gathered}
B_{1}=\frac{p_{e}-p_{i}}{r_{0}^{2}-r_{1}^{2}} r_{1}^{2} r_{0}^{2}, C_{1}=\frac{(1-v)\left(p_{e} r_{0}^{2}-p_{i} r_{1}^{2}\right)}{2(1+v)\left(r_{0}^{2}-r_{1}^{2}\right)}, \\
A_{3}=\frac{(2-v)\left(p_{e} r_{0}^{2}-p_{i} r_{1}^{2}\right)}{3(1+v)\left(r_{0}^{2}-r_{1}^{2}\right)}, \delta=-\frac{v\left(p_{e} r_{0}^{2}-p_{i} r_{1}^{2}\right) h}{G(1+v)\left(r_{0}^{2}-r_{1}^{2}\right)} .
\end{gathered}
$$

The displacements and stresses will be equal to:

$$
\begin{gathered}
u_{\rho}=-\frac{1}{2 G\left(r_{0}^{2}-r_{1}^{2}\right)}\left[\frac{\left(p_{e}-p_{i}\right) r_{1}^{2} r_{0}^{2}}{\rho}+\frac{(1-v)\left(p_{e} r_{0}^{2}-p_{i} r_{1}^{2}\right)}{1+v} \rho\right], \\
u_{z}=\frac{v\left(p_{e} r_{0}^{2}-p_{i} r_{1}^{2}\right)}{G(1+v)\left(r_{0}^{2}-r_{1}^{2}\right)}(z-h), \sigma_{\rho}=\frac{r_{1}^{2} r_{0}^{2}}{r_{0}^{2}-r_{1}^{2}} \frac{p_{e}-p_{i}}{\rho^{2}}-\frac{p_{e} r_{0}^{2}-p_{i} r_{1}^{2}}{r_{0}^{2}-r_{1}^{2}}
\end{gathered}
$$




$$
\sigma_{\varphi}=\frac{r_{1}^{2} r_{0}^{2}}{r_{0}^{2}-r_{1}^{2}} \frac{p_{e}-p_{i}}{\rho^{2}}-\frac{p_{e} r_{0}^{2}-p_{i} r_{1}^{2}}{r_{0}^{2}-r_{1}^{2}}, \sigma_{z}=\tau_{z \rho}=0
$$

The equilibrium of a circular cavity cylinder (casing), which is under the action of uniformly distributed tangent forces applied to the front cylindrical surfaces (case of the first boundary value problem) is considered (Fig. 4). The task is accomplished by the stress function method.

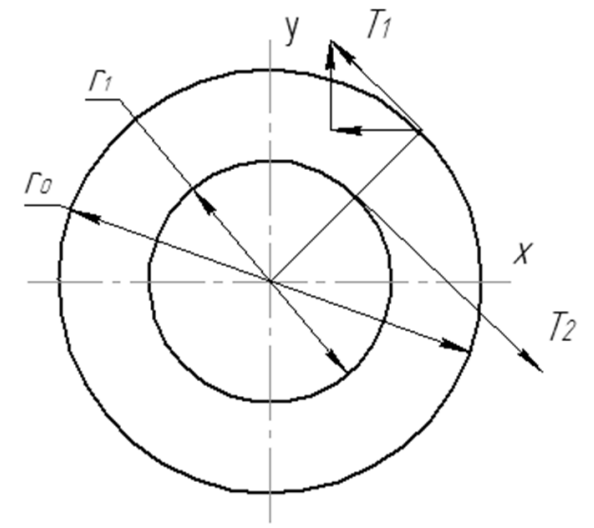

Fig. 4 Scheme of uniformly distributed tangent forces applied to the front cylindrical surfaces

$$
\begin{aligned}
& \varphi(z)=-\frac{1}{2 \pi(1+\chi)} \sum_{k=1}^{m}\left(V_{1 k}+i V_{2 k}\right) \ln \left(z-z_{k}\right)+\varphi^{*}(z), \\
& \psi(z)=-\frac{\chi 1}{2 \pi(1+\chi)} \sum_{k=1}^{m}\left(V_{1 k}+i V_{2 k}\right) \ln \left(z-z_{k}\right)+\psi^{*}(z),
\end{aligned}
$$

where:

$V$ - is the principia vector of surface forces applied to the entire surface;

$\varphi^{*}(z), \psi^{*}(z)-$ holomorphic functions;

$\chi=\frac{\lambda+3 \mu}{\lambda+\mu}=3-4 v$,

$\lambda, \mu$-lame constans.

The principal force vectors $\rho=r_{1}$ and $\rho=r_{0}$ applied to each of the surfaces and are individually equal to zero, so from the formulas (6) and (7) follows that the functions $\varphi(z)$ and $\psi(z)$ are holomorphic inside the ring (see Fig. 4). These functions $\varphi(z)$ and $\psi(z)$ are determined by the boundary conditions

$\varphi\left(t_{1}\right)+t_{1} \overline{\varphi^{\prime}\left(t_{1}\right)}+\overline{\psi\left(t_{1}\right)}=f\left(t_{1}\right)+c_{1}$ on the ring $\rho=r_{0}$

$\psi\left(t_{2}\right)+t_{2} \overline{\varphi^{\prime}\left(t_{2}\right)}+\overline{\psi\left(t_{2}\right)}=f\left(t_{2}\right)+c_{2}$ on the ring $\rho=r_{1}$ where:

$$
\begin{aligned}
& f\left(t_{1}\right)=i \int_{0}^{l}\left(T_{1}+i T_{2}\right) d l=i r_{1} T_{1} \int_{0}^{\alpha}(-\sin \alpha+i \cos \alpha) d \alpha= \\
& \quad i T_{1}\left(t_{1}-r_{0}\right), \\
& f\left(t_{2}\right)=i T_{2}\left(t_{2}-r_{1}\right) .
\end{aligned}
$$

Due to the equality of moments, the relations between the tangent forces $T_{1}$ and $T_{2}$ have the form $T_{1} r^{2}{ }_{0}=T_{2} r_{1}^{2}$. In the circular ring the functions $\varphi(z)$ and $\psi(z)$ are taken in the form

$$
\varphi(z)=0, \psi(z)=\frac{b_{1}}{z} .
$$

By (9) in boundary conditions $\overline{b_{1}}=i T_{1} r_{0}^{2} ; c_{1}=i T_{i} r_{0}$ are found, wherefrom $b_{1}=i T_{1} r_{0}^{2}$.

Thus $\varphi(z)=0, \psi(z)=-i T_{1} r_{0}^{2} \frac{1}{z}$.

So taking into account:

a) relationships that provide with a complex idea of the stress tensor components at a plane deformed environment state

$$
\begin{gathered}
\sigma_{11}+\sigma_{22}=2\left[\varphi^{\prime}(z)+\overline{\varphi^{\prime}(z)}\right]=4 \operatorname{Re}\left[\varphi^{\prime}(z)\right], \\
\sigma_{22}-\sigma_{11}+2 i \sigma_{12}=2\left[\bar{z} \varphi^{\prime \prime}(z)+\psi^{\prime}(z)\right] ;
\end{gathered}
$$

b) analytical function $z=\omega(\xi)$; c) by entering new notations

$\varphi(z)=\varphi \cdot(\omega(\xi))=\varphi_{1}(\xi), \psi(z)=\psi \cdot(\omega(\xi))=\psi_{1}(\xi)$, it is found out that the functions $\varphi(\xi), \psi_{1}(\xi)$ are holomorphic in the area of a unit circle $|\xi|<1$ in the plane $\xi$,

d) formulas

$$
\begin{gathered}
\sigma_{\rho \rho}+\sigma_{\vartheta \vartheta}=\sigma_{11}+\sigma_{22}, \\
\sigma_{\vartheta \vartheta}-\sigma_{\rho \rho}+2 i \sigma_{\rho \vartheta}=\left(\sigma_{22}-\sigma_{11}+2 i \sigma_{12}\right) e^{2 i \alpha},
\end{gathered}
$$

it is found out

$$
\begin{aligned}
\sigma_{\rho \rho}+\sigma_{\theta \theta} & =2\left[\phi_{1}(\zeta)+\overline{\phi_{1}(\zeta)}\right], \\
\sigma_{\theta \theta}-\sigma_{\rho \rho}+2 i \sigma_{\rho \theta} & =\frac{2 \zeta^{2}}{\rho^{2} \overline{\omega^{\prime}(\zeta)}}\left[\overline{\omega(\zeta) \phi_{1}^{\prime}(\zeta)}+\omega^{\prime} \psi_{1}(\zeta)\right],
\end{aligned}
$$

where:

$\sigma_{\rho \rho}, \sigma_{\vartheta \vartheta}, \sigma_{\rho \vartheta}-$ are components of the stress tensor in polar coordinates;

$$
\Phi_{1}(\xi)=\varphi^{\prime}(z)=\Phi(z) ; \Psi_{1}(\xi)=\psi^{\prime}(z)=\Psi(z) .
$$

From the formulas (10) there is

$$
\sigma_{\rho \rho}+\sigma_{\theta \theta}=0 ; \sigma_{\rho \rho}-\sigma_{\theta \theta}-2 i \sigma_{\rho \theta}=-2 i T_{1} r_{0}^{2} \frac{1}{z \bar{z}} \text {. }
$$

From here it is found out that

$$
\sigma_{\rho \rho}=\sigma_{\theta \theta}=0, \sigma_{\rho \theta}=\frac{T_{1} r_{0}^{2}}{\rho^{2}} .
$$

On the other hand from the formula

$$
u_{\rho}+i u_{\theta}=\frac{\bar{\zeta}}{\rho} \frac{\omega^{\prime}(\zeta)}{\left|\omega^{\prime}(\zeta)\right|}\left(u_{1}+i u_{2}\right)
$$

taking into account the formula

$$
2 \mu\left(u_{1}+i u_{2}\right)=\chi \varphi(z)-z \overline{\varphi^{\prime}(z)}-\overline{\psi(z)}
$$

it will be obtained

$$
2 \mu\left(u_{\rho}+i u_{\theta}\right)=i \frac{T_{1} r_{0}^{2}}{\rho},
$$

whence $u_{\rho}=0, u_{\theta}=\frac{T_{1} r_{0}^{2}}{2 \mu} \frac{1}{\rho}$.

Therefore, through the task accomplishing by the method of stress function, the equilibrium of a circular cavity cylinder (casing), which is under the action of uniformly distributed tangent forces applied to the front cylindrical surfaces, was considered. Considering the above solutions, we can conclude that this method can be used to investigate particular cases of the stress-strain state of the casing. Therefore, due to the task performed by the method of stress function, the equilibrium of the cylinder (casing) of the circular cavity, which is under the action of uniformly distributed tangent forces applied to the front cylindrical surfaces, was considered. Considering the above solutions, we can conclude that this method can be used to investigate individual cases of stress-strain state of the casing.

The following main results were obtained: the analysis of the reliability of oil and gas wells showed that the loss of serviceability of the housings and pump columns is mainly due to the structural and technological failure of the reliability and tightness of their connecting threaded connections.

\section{CONCLUSIONS}

On the basis of theoretical and experimental studies, an important scientific and technical problem of increasing the working capacity of threaded joints of casing and pumping tubes by improving the joints of sealing connections, taking into account operational loads, has been solved, which ensures the reliability of operation and reliability. 
At the same time, the following main results were obtained: the necessity to develop the clutch threaded connections in the direction of increasing their tightness, improving the methods of calculation and designing the parameters of their efficiency.

The pipe is considered as a thick-walled cylinder (cylindrical thick-walled shell) that carries a complex load, and the method of determining its axisymmetric stress-strain state using the equations of three-dimensional elastic theory is improved. A complete system of equations was obtained for solving the problems of the mechanics of a deformed solid in displacements and stresses. The obtained results allow us to determine the stresses and strains in the casing or pumping pipe under the influence of complex loading. A system of equations for cylindrical shells whose stress state is caused by a defective stress-strain state is obtained. The regularities of the influence of design and operational factors on the performance of the threaded joints of pipes, which are the most responsible element for the reliability and durability of the columns, have been obtained. The graphoanalytical study of the geometrical parameters of the threaded joints, in particular the threaded unloading grooves, allowed to create a variational multidimensional graphoanalytic model for optimizing the geometric parameters.

\section{REFERENCES}

[1] A.P. Farr. "Torque requiments for rotary-shouldered connections and selection of Connetions for drill collars". The American Society of Mechanical Engineers, vol. 57, 1957, 305p.

[2] I.D, Faux, M.J. Pratt. Computational Geometry for Design and Manufacture. Chichester, West Sussex, John Willey \& sons, 1979.

[3] I.D. Faux, M.J. Pratt. Computational Geometry for Design and Manufacture (Mathematics and Its Applications) Ellis Horwood; New Ededition, 1981.

[4] A. Fox. Computational geometry. Application in design and production. Moskwa, 1982.

[5] V. Hauk., H. Hillemann, H. Kochler. "Schwingende Langskraft und Drehmoment beanspruchung von Bohrgestanden". Erdol und Kohle - Erdgas - Petrochemie, vol. 7, 1965, pp. 514-552.

[6] E. Kryzhanovsky, V. Ivasiv, V. Vasylyshyn, R. Rachkevich. "Fatigue life of threaded pipe connections in curved sections of wells". Scientific Bulletin National Mining University, vol. 5, 2015, pp. 14-21.

[7] O. Onysko, L. Shkitsa, I. Taras. "Geometric analysis of manufacturability of conical locking thread" in Proc. Progressive Technologies in Engineering RTME-2019, 2019, pp. 216-218.

[8] O. Onysko, V. Panchuk, V. Vryukalo. "Threaded cutters with straight-cut cutting edge adjusted by value of front angle" in Proc. Progressive Technologies and Systems of Mechanical Engineering, 2014, pp. 10-14.
[9] O. Onysko, L. Boruschak, V. Kopey. "Ensuring the precision of manufacturing casing thread by applying parametric design of the profile of the cutting section of threaded tools in the environment of the Delphi programming system". Scientific Bulletin of the National Technical University of Oil and Gas, vol. 2 (20), 2009, pp. 50-53.

[10] O. Onysko. "Methods of ensuring the accuracy of production of threaded ends of pipes of oil and gas assortment". Exploration and Development of Oil and Gas Fields, vol. 3 (52), 2014, pp. 107-115.

[11] R. Rachkevich. "Stress-deformed state of the compressed drill string in the horizontal wellbore". Exploration and Development of Oil and Gas Fields, vol. 3 (44), 2012, pp. 70-77.

[12] S. Savula, V. Kolodiy, E. Kharchenko. "Estimation of the influence of oscillations of the tubing column on the conditions of operation of the joints". Scientific Bulletin of the National Technical University of Oil and Gas, vol. № 2 (8), 2004, pp. 116-125.

[13] L. Trischmon. "Methods for the Improvement of Drillcoller Jihst Eveluated bu Full size Fatigues tests". Drilling and Production Practice, vol. 5, 1972, p. 175.

[14] V. Vasylyshyn. "The effect of screwing torque on the fatigue resistance of locking threaded connections of drill pipes". Exploration and Development of Oil and Gas Fields, vol. №4 (37), 2010, pp. 55-58.

[15] V. Vasylyshyn. "Analysis of force factors in the elements of the threaded connection under counterload method". Exploration and Development of Oil and Gas Fields, vol. №2 (27), 2008, pp. 62-66

[16] V. Vasylyshyn. "Graphoanalytic modeling of surfaces of threaded unloading grooves of threaded joints of pipes of oil assortment". Oil and gas industry, vol. 36, 1999, pp. 167-173.

[17] V. Vasylyshyn. "Analysis of force factors in the elements of a threaded connection under one-way loading method". Exploration and Development of Oil and Gas Fields, vol. №1 (34), 2010, pp. 106-108.

[18] V. Vasylyshyn, I. Paliychuk, P. Shcheglyuk, S. Roketsky. "Analysis of problems and ways to increase the reliability and tightness of clutch joints casing". Exploration and Development of Oil and Gas Fields, vol. №1 (42), 2012, pp. 169-176.

[19] V. Vasylyshyn. "An algorithm for calculating the areas of annular sections of surfaces of threaded unloading grooves". Scientific Bulletin of the National Technical University of Oil and Gas, vol. №2 (24), 2010 pp. 77-80.

[20] V. Vasylyshyn. "Analysis of the Impact of the Threaded Unloading Groove on the Fatigue Resistance of Castle Thread Joints" in Proc. Innovative Potential of Ukrainian Science - XXI Century, 2010, pp. 67-70.

[21] V. Vasylyshyn. "Analysis of the Impact of Screwing Torque on the Fatigue Resistance of Threaded Joints of Oil and Gas Equipment" in Proc. Research Development 2010, 2010, pp. 16-20. 
[22] V. Vasylyshyn. "Theoretical substantiation of the surface shapes of threaded unloading grooves of threaded pipe joints" in Proc. Oil and Gas of Ukraine 2000, 2000, pp. 297-299.

[23] V. Vasylyshyn. "Ways to improve the reliability and tightness of clutch joints of casing" in Proc. Space and Time of Modern Science, 2013, pp. 37-39.
[24] H. Wiegand. "Die Dauerhaltbarkcit von Gewindever bindungen mit ISO". Profil in Abhangigkeit von der Einschraubtiefe, vol. 16, 1964, pp. 3-16.

\author{
Vitalii Vasylyshyn \\ ORCID ID: 0000-0002-0367-1198 \\ Ivano-Frankivsk National Technical University \\ of Oil and Gas \\ Karpatska St. 15, Ivano-Frankivsk, Ukraine \\ e-mail: v.vasylyshyn@nung.edu.ua
}

Iryna Taras

ORCID ID: 0000-0002-9865-0778

Ivano-Frankivsk National Technical University

of Oil and Gas

Karpatska St., 15, 76019, Ivano-Frankivsk, Ukraine

e-mail: i.taras@nung.edu.ua

\section{Iryna Bekish}

ORCID ID: 0000-0003-1910-9009

Ivano-Frankivsk National Technical University

of Oil and Gas

Karpatska St., 15, 76019, Ivano-Frankivsk, Ukraine

e-mail: i.bekish@nung.edu.ua

\section{Olena Kornuta}

ORCID ID: 0000-0002-0626-888X

Ivano-Frankivsk National Technical University

of Oil and Gas

Karpatska St., 15, 76019, Ivano-Frankivsk, Ukraine

e-mail: o.kornuta@nung.edu.ua

\section{Volodymyr Kornuta}

ORCID ID: 0000-0002-3345-2578

Ivano-Frankivsk National Technical University

of Oil and Gas

Karpatska St., 15, 76019, Ivano-Frankivsk, Ukraine

e-mail:v.kornuta@nung.edu.ua 